\title{
Escrituras de Drummond: Arte em exposição (Questões de iconicidade e abstração)
}

\author{
Márcia Maria Sant'Ana JÓE \\ (Universidade de São Paulo)
}

RESUMO: Este estudo pretende apontar diferenças entre a iconicidade e a abstração em quatro pinturas do livro intitulado Arte em exposição, de Carlos Drummond de Andrade, publicado em 1990. O sentido desses objetos pictóricos será construído a partir de categorias específicas da semiótica.

PALAVRAS-CHAVE: figuratividade; iconicidade; abstração; sentido; pintura

\begin{abstract}
This study has the intention to point up differences between the iconicity and the abstraction in four paintings of Carlos Drummond book Art in Exhibition, published in 1990. The meaning of these picturesque objects will be constructed from specific semiotics categories.
\end{abstract}

KEYWORDS: figurativity; iconicity; abstraction; meaning; painting 
$\mathrm{O}$ gênero retrato será abordado, inicialmente, segundo artigo publicado com o título Semiótica figurativa e semiótica plástica, de Greimas (1984), em que o autor se baseia em estudos de Floch, de Felix Thülermann e de outros semioticistas que participaram do atelier de estudo visual. Fundamentados em princípios discutidos por Greimas, vamos nos apoiar, sobretudo, em questões que dizem respeito à iconicidade da representação de um objeto visual rumo à abstração. Posteriormente, consideraremos sob a ótica de Anne Beyaert (2002) a mesma questão da representação, mas sobre o gênero retrato, acrescentando instâncias particulares de análise desse gênero, como: o rosto, a cabeça e, sobretudo, o olhar. Atentaremos, ainda, para a relação fundo e figura, e à boa distância para a contemplação do quadro, enquanto princípio de presença, significação e percepção enunciador-enunciatário.

Sobre a questão da iconicidade, o artigo de Greimas (1984:22) diz respeito às relações entre o figurativo e o plástico. Segundo essa teoria de representação da visualidade do objeto plástico, o sistema de representação icônico configura uma relação de signo motivado, ou seja, de acordo com a realidade ou com o referente representado. Assim, nas palavras de Greimas,

[...] essa relação pressupõe certa identidade, total ou parcial, entre os traços e as figuras do representado e do representante. Nessas condições - e malgrado os refinamentos que séculos de reflexão carrearam para os conceitos de 'imitação' e de 'natureza' - a atividade do pintor, por exemplo, deve ser compreendida como um conjunto de procedimentos que são cobertos pelo termo imitação e que visam a reproduzir o essencial dos traços da 'natureza'. Vê-se que essa atividade pressupõe, da parte do pintor imitador, uma análise implícita bastante acurada da 'natureza' bem como o reconhecimento das articulações fundamentais do mundo natural que pensa estar reproduzindo (Greimas, 1984:22-23).

No entanto, isso leva Greimas (1984:79) a considerar que a semiótica figurativa concerne muito mais a uma relação de semelhança com o mundo natural representado que a uma relação icônica, pois a leitura de um objeto depende da natureza social de cada cultura que instrui uma visão particular de mundo.

A leitura iconizante pressupõe um significante e um significado que produzirá um signo passível de interpretação em que esses objetos visuais assumem diferentes graus de densidade dos traços e de organização visuais. A variação desses traços visuais permitirá a leitura do objeto que se aproxima do mundo natural, assumindo uma leitura figurativa. Todavia, quanto mais os traços visuais, constituintes do conjunto dos formantes figurativos, se afastarem de uma representação dos objetos do mundo natural, mais a leitura das figuras será de difícil reconhecimento, constituindo, portanto, uma maior abstração desse objeto. Por conseguinte, podemos dizer que a abstração e a iconicidade representam graus variáveis de leitura figurativa e que não são duas maneiras fundamentalmente diferentes de pintar.

Sendo assim, segundo Greimas (1984:29) a interpretação de um objeto semiótico depende da leitura que o constrói, pois quando o objeto se afasta da imagem do mundo figurativizado, caminha para a ponta oposta da mesma escala representativa de abordagem visual, apresentando uma desconstrução da iconicidade que ruma à leitura estética. Portanto, um objeto terá "efeitos de sentido", enquanto objeto 
significante segmentável passível de ser analisado em partes menores, constituintes de um todo.

Para nosso propósito, enfocaremos a representação de um objeto visual, segundo seu grau de iconicidade e de abstração, por meio de um estudo apurado de Anne Beyaert (2002), sobre uma semiótica do gênero retrato, em que a autora aborda três instâncias: rosto, cabeça e olhar. Poderemos refletir em torno dos preceitos discutidos por ela no intuito de analisar se eles são válidos para o nosso objeto de análise, principalmente em relação às peças do poema "Arte em exposição" e das pinturas aí referidas que assumem esse gênero. (A autora sustenta seu trabalho de reflexão sobre propostas de renomados semioticistas como Jacques Fontanille e Claude Zilberberg.)

Começamos por concordar com Beyaert quando, baseada nas idéias de Paul Ricoeur, ela se opõe à clássica definição desse gênero de pintura, que se caracterizaria como obra de representação semelhante a alguém, ao passo que ela prefere apontá-lo como uma referência a alguém, ou como o próprio Ricoeur designou, "un surcroît".

Por essa via, o principal efeito obtido não é mais o de similitude do retrato à pessoa nele pintada, mas o efeito de presença daquele que está ausente. Essa é uma das questões mais importantes que nos levam a assumir uma concepção semiótica motivada pela relação entre dois sujeitos, ou seja, uma motivação relacional. Dessa maneira, podemos dizer que a autora concebe as mesmas idéias de que se valeu Greimas (1984) sobre a semiótica figurativa.

Anne Beyaert (2002) examina o gênero do retrato sob a perspectiva da semiótica tensiva a fim de perceber efeitos de presença, para num segundo momento examinar em quais das três instâncias - o rosto, a cabeça e o olhar - se estabelece a presença do outro, pois cada qual possui uma maneira de se comportar na relação enunciador- enunciatário.

Primeiramente, vamos estabelecer algumas caracterizações que corroboram a semiótica da presença no gênero do retrato. A "boa distância" confirma-se como critério de presença, significação e percepção, assim, a "boa distância" mobiliza, sobretudo, entre todos os sentidos, a percepção do sentido visual que, conjugada com informações afetivas, desencadeia a expressão das emoções contemplativas do sujeito.

Ainda dentro dessa categoria, os pintores restringem o campo da "boa distância”, ou distância pessoal. A variação entre $45 \mathrm{~cm} \mathrm{e} \mathrm{1,25} \mathrm{cm} \mathrm{age} \mathrm{sobre} \mathrm{a}$ percepção para despertar o sentido do olhar do sujeito - o qual é dotado de sentir - na observação de texturas, formas, volumes e outros detalhes menores. A profundidade permite também desenvolvermos empatia, compreensão e identificação para com aquilo que vemos.

Antes de passarmos para outra caracterização desse gênero é válido discutir como tal categoria pode influenciar os objetos que estamos analisando. São quatro quadros relativos ao retrato que compõem as peças do poema de Drummond: Retrato de madame Hébuterne (Modigliani), Auto-retrato (Soutine), Retrato do casal Arnolfini (Jan van Eyck) e Gioconda (Da Vinci).

Talvez possamos dizer que o antigo conceito de retrato como representação mimética ou icônica perdura, sobretudo, no movimento Renascentista, como em Retrato do casal Arnolfini (Fig. 3) e Gioconda (Fig. 4). Todavia, os quadros Retrato de madame Hébuterne (Fig. 1) e Auto-retrato (Fig. 2) apresentam mais que uma similitude com os 
sujeitos retratados, mas mostra, além disso, o intuito de restituir uma presença “estilizada" que ruma à abstração do sujeito da enunciação. Todos eles, porém, são dotados de presença enunciativa, cada qual dentro de sua especificidade.

A próxima instância diz respeito à figura e ao fundo. Para Beyaert (2002) existe certa rivalidade entre elas, pois a figura deveria prevalecer sobre o fundo para destacar a identidade do ser e não se reduzir à massa material. $\mathrm{Na}$ verdade, o fundo deve permanecer neutro em relação à figura que avança, se destaca e chama a atenção do enunciatário. Nesse momento, a "boa distância" age como coadjuvante dessa categoria, destacando a figura do fundo e garantindo a afetividade e a compreensão daquele que vê.

$\mathrm{Na}$ fronteira entre figura e fundo prevalece, segundo comentário de Jean-Luc Nancy (Nancy apud Beyaert, 2002:91), o contorno como fator distintivo e de identificação entre eles, tanto quanto o monocromatismo e a uniformidade das cores e texturas.

Nas peças que analisamos, ocorre fundo monocromático na pintura Autoretrato (Fig. 2) e fundo bicromático em Retrato de madame Hébuterne (Fig. 1). $\mathrm{O}$ primeiro quadro é concebido sobre uma superfície monocromática preta, embora haja conjuntamente o recurso do contorno para reforçar o sujeito retratado. O outro quadro, no entanto, apresenta as cores verde e marrom que compõem o retrato do sujeito, compondo também o seu fundo com o mesmo cromatismo.

Retrato de madame Hébuterne concede maior atenção ao retrato, constituindo presença intensiva para o rosto do sujeito retratado, pois o rosto posiciona-se do meio para a parte superior do quadro e abrange uma porção significativa da tela, influenciando assim a observação do enunciatário. $O$ fundo bicromático possibilita a prevalência da figura sobre esse fundo quase neutro para a figura se destacar, pertencendo portanto à escala da neutralidade, já que não se encontram objetos que possam concorrer com o sujeito do retrato, compondo um quadro que é o retrato em si e por si mesmo.

Já o quadro Retrato do casal Arnolfini (Fig. 3) possui um cenário rico em detalhes simbólicos que requer uma maior atenção do enunciatário, como a inscrição do próprio pintor sobre um pequeno espelho, circundado pelos passos da via sacra de Cristo, além de outros detalhes como a minúcia dos pêlos do cachorro. Esse retrato destaca não só o casal, mas o conjunto fundo e figura, como narrativas que se complementam e caminham concomitantemente uma ao lado da outra.

Gioconda (Fig. 4) revela uma sutil paisagem em segundo plano que possui dois caminhos tortuosos, cada um de um lado da Gioconda, que rumam perspectivamente às montanhas geladas. A paisagem é construída no jogo de claro e escuro, esfumaçada e sem muitos contornos. A desigualdade dessa paisagem é evidente se compararmos os lados direito e esquerdo, fato que pressupõe um possível adicionamento tardio de um dos lados, posteriormente à figura retratada.

Portanto, observamos que, quanto maior a neutralidade do fundo, mais a figura tornam-se evidente, como num procedimento de triagem que concentra a presença intensa da figura, possibilitando ao enunciatário conceder maior atenção ao retrato, em contraposição a uma pintura carregada de informações ou formantes plásticos, que dispersam a observação do enunciatário. 
Beyaert encontrou nas idéias de Jean-Marie Pontévia (Pontévia apud Beyaert, 2002:91) um novo conceito para definir o gênero retrato como sendo uma estrutura ou sistema que se organiza ao redor de uma figura. Nesse raciocínio, acreditamos que além do pintor, também o poeta deve priorizar seu objeto para configurar, no território de presença, sentidos e metáforas.

Aqui, as peças analisadas enfatizam cada qual seu objeto para determinar um possível sentido. Voltemos aos exemplos de Retrato de madame Hébuterne (Fig. 1) e Auto-retrato (Fig. 2), pois são o grau máximo de presença intensiva do ser por sobre a neutralidade de um fundo, em contraposição ao Retrato do casal Arnolfini (Fig. 3) que se posiciona na ponta contrária da escala da neutralidade. Este, além de enfatizar a polissemia de sentidos, desloca a atenção do sujeito em relação ao casal retratado. Entretanto, há várias justificativas para continuar sendo um retrato que merece especial atenção do enunciatário, uma vez que se insere, no fundo da tela, a marca da enunciação do enunciador por escrito: Jan van Eyck esteve aqui, em latim.

Uma observação, entretanto, deve ser feita. A maior parte dos retratos aqui comentados apresenta o rosto da figura posicionado no eixo superior do quadro. Assim, podemos dizer que a parte central do quadro coloca em evidência o mais importante para o pintor, como também influencia a observação do enunciatário. Isso significa que adentramos num outro item sobre a caracterização instituída ao retrato, aos detalhesemblema segundo Daniel Arasse (Arasse apud Beyaert, 2002:92).

Vale dizer ainda que essa categoria torna-se outra razão para o quadro de Van Eyck (Fig. 3) ser observado com cuidado, pois, apesar de os objetos metafóricos tirarem a atenção do observador, de certo modo eles instituem presença afetiva, condensando o sentido do quadro. Dessa maneira, gera-se uma situação de disputa entre a presença da figura principal e os outros elementos da cena. Todavia, esse estado condiz com a maioria dos quadros retratados e com a afirmação de Jean-Luc Nancy, que defende o retrato do sujeito como figura principal da cena, sem muitos objetos que interfiram na atenção daquele que o contempla.

Ademais, ocorre que o processo metafórico tem por finalidade a recuperação da significação da figura como ator e não apenas como actante. Ao ator será incutida, pelo pintor, intensidade de presença por meio de "semas de individuação", segundo as definições de Greimas e Courtés (apud Beyart, 2002: 92-93).

Agora, adentramos à primeira instância que busca condições para analisar a presença semiótica. A figura actorial pode ser manifestada somente pelo rosto. Este modo de retratar dificulta, segundo os semioticistas, uma aproximação, embora tenha o poder de exercer maior influência sobre o observador. Um bom exemplo é a figura famosíssima da Gioconda que, tão fascinante e intrigante ao mesmo tempo, abarca dificuldade de aproximação e influência sobre o enunciatário. As características essenciais contidas na estrutura desse retrato ainda continuam sendo interrogadas e talvez a semiótica possa, respeitando o encantamento da arte, contribuir para explicar esses efeitos de sentido. Uma das dificuldades que perduram em torno do gênero retrato é a temporalidade, considerando-se que o presente, amanhã, será passado. Surge, assim, uma configuração de resistência ao tempo. Outra dificuldade estende-se à variação dos afetos interoceptivos e exteroceptivos no âmbito da enunciação enunciada. Investir na predominância de traços íntimos representa privilegiar a proprioceptividade, ou seja, tanto um como outro. 
Por outro lado, para garantir a presença do retrato Gioconda (Fig. 4) é necessário deixar que o enunciatário participe analisando comparativamente os quesitos referentes à simetria entre as partes do modelo. Por exemplo, os quadros Retrato de madame Hébuterne (Fig. 1) e Auto-retrato (Fig. 2) nos permite conferir que primeiro modelo se apresenta, segundo Anne Beyaert, numa pose frontal e o segundo, numa pose prototípica em que dorso e face estão em diferentes posições.

Uma segunda instância da presença é a referente à cabeça. Diferentemente da face, a cabeça é um sistema estrutural dependente do corpo, como define Gilles Deleuze (Deleuze apud Beyaert, 2002:97). Além disso, essa parte do corpo, que nos aproxima dos animais, tende à generalidade, em oposição à particularidade da face.

Há também uma distinção entre as duas em relação ao tempo. A cabeça apresenta uma aspectualidade durativa, enquanto a face apresenta transformações devido às expressões fisionômicas. Todavia, em relação ao espaço se igualam, já que ambas proporcionam, dentro da distância e da referência de fundo, efeito de presença que aproxima o enunciatário do enunciador.

A terceira e última instância refere-se à presença do olhar, que subsume a face e a cabeça. Voltemos um pouco à definição de retrato. Se o retrato se organiza em torno de uma figura, conseqüentemente, o olhar é o ponto culminante da presença que nos toca. Recorremos como exemplo, ao quadro Retrato de madame Hébuterne (Fig. 1). $\mathrm{O}$ sujeito apresenta o olhar fixo no sujeito observador do quadro.

Dissemos no início que o efeito de presença manifesta-se tornando o ausente presente, assim o efeito de presença nesses dois quadros manifesta-se sob a ausência, corroborando o nível de expressão potencializada como o que mais chama a atenção do enunciatário. Isso não quer dizer que nos outros quadros não haja efeito de presença, pois o olhar ao lado de objetos também produz o mesmo efeito, mas talvez não com a mesma intensidade.

Concluímos dizendo que o olhar não se manifesta sozinho no retrato, com o propósito de reforçar o efeito de presença e de sentido que se quer atingir. O motivo principal é o de estabelecer uma reciprocidade em que o enunciador toque o enunciatário e este se deixe tocar. O olhar do quadro de Modigliani (Fig. 1) e de Da Vinci (Fig. 4) só demonstram efeito de presença e de sentido, porque não se apresentam sozinhos e recorrem a outros elementos como nariz, boca, orelha para completar-lhes o sentido.

Pudemos perceber, pela análise dos quatro quadros, que Retrato do casal Arnolfini (Jan van Eyck) e Gioconda (Da Vinci) tendem à iconicidade ou à figuratividade que representa a imagem conforme o objeto representado e que, de outra parte, Retrato de madame Hébuterne (Modigliani) e Auto-retrato (Soutine) demonstram uma tendência à abstração, embora possam ser identificados.

Em ambos os casos, o que os diferencia é o grau de figuratividade conferido ao objeto retratado. Por meio da figuratividade foi possível realizar uma análise que revelasse a produção de sentido expressa pelas estruturas constituintes da arte visual.

Esse trabalho teve a intenção de demonstrar a possibilidade de utilizar um aparato teórico que pudesse ser aplicado em diferentes textos de diferentes linguagens e explicitar como a semiótica pôde contribuir na reflexão sobre a busca de sentido presente no texto. Por isso, a semiótica tem-se preocupado também com as organizações abstratas do sentido, na medida em que se ultrapassam as questões mais superficiais do 
texto. Assim, a teoria semiótica tornou-se produtiva, devido ao seu arcabouço teórico e metodológico já consolidado e provado em descrições de outras linguagens, quer verbais ou não-verbais.

\section{REFERÊNCIAS BIBLIOGRÁFICAS}

ANDRADE, Carlos Drummond de. Arte em exposição. Rio de Janeiro: Editora Record/ Salamandra, 1990.

BEYAERT, Anne. "Une seémiotique du portrait". Université de Limoges: Tangence, $\mathrm{n}^{\circ}$ 69, 2002: 85-101.

DA VINCI, Leonardo. Gioconda. Paris: Louvre, 1503-1506.

EYCK, Jan van. Retrato do casal Arnolfini. Óleo sobre tela, 82,2 x $60 \mathrm{~cm}$. London: National Gallery, 1434.

FLOCH, Jean-Marie. Petites mythologies de l'oeil et de l'esprit : pour une sémiotique plastique. Amsterdam : Hadès-Benjamins, 1985.

."L'art abstrait". Actes Semiotiques: Bulletin. 1987.

FONTANILLE, Jacques. Le malaise. In. Il discorso delle salute. Gianfranco Marrone (dir.), Roma: Meltemi, 2006.

[online] Disponível na Internet via WWW.URL:

http://unilim.fr/pages_perso/jacques.fontanille/Fontanille-divers.html Arquivo consultado em DIA/MES/ANO.

FONTANILLE, Jacques \& ZILBERBERG, Claude. Tensão e significação. Tradução de Ivã Carlos Lopes, Luiz Tatit e Waldir Beividas. São Paulo: Discurso Editorial/ Humanitas, 2001.

GREIMAS, Algirdas Julien. Sobre o sentido. Petrópolis, Vozes: 1975. 1984.

"Semiótica figurativa e semiótica plástica". n4. In: Significação, Araraquara,

Da imperfeição. Prefácio e tradução de Ana Claudia de Oliveira. São Paulo: Hacker Editores, 2002.

GREIMAS, Algirdas Julien \& COURTÉS, Joseph. Dicionário de Semiótica. Tradução de Alceu Dias Lima et alii. São Paulo: Cultrix, 1979.

HOUAISS, Antônio. Dicionário Houaiss da Língua Portuguesa. Rio de Janeiro: Ed. Objetiva, 2004.

MODIGLIANI, Amadeo. Retrato de Madame Hébuterne. Óleo sobre tela, $55 \mathrm{~cm}$ x 38 cm. Estados Unidos: Coleção Particular, 1919.

OLIVEIRA, A. C. de. Semiótica Plástica. São Paulo: Hacker Editores, 2004.

SOUTINE, Chaïm. Auto-Retrato. Óleo sobre tela, $81 \mathrm{~cm}$ x $43 \mathrm{~cm}$. New York: Museum of Modern Art, 1922-23. 


\section{ANEXo}

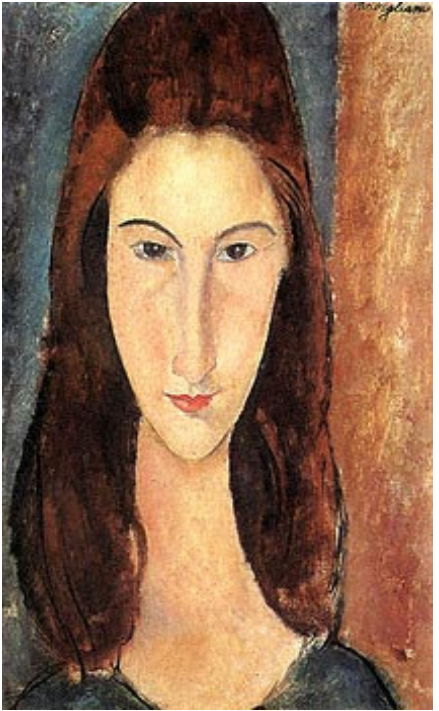

Fig. 1 Retrato de madame de Hébuterne (Modigliani)

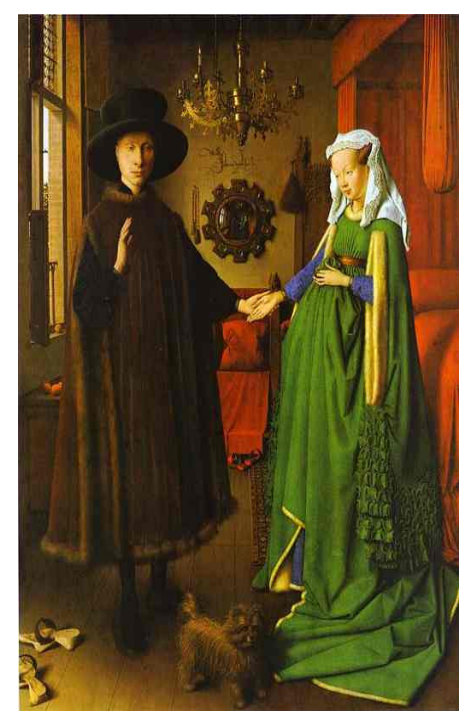

Fig. 3 Retrato do casal Arnolfini (Jan Van Eyck).

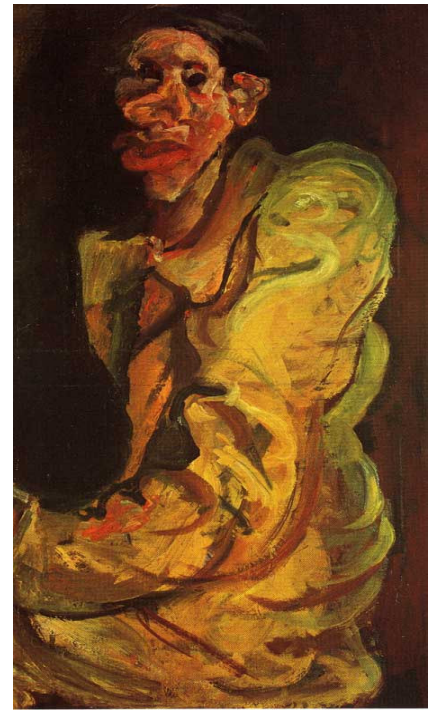

Fig. 2 Auto-retrato (Soutine).

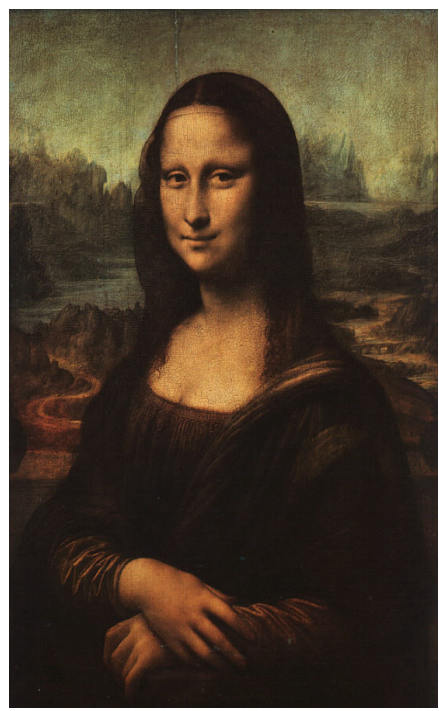

Fig. 4 Gioconda (Da Vinci). 
Como citar este artigo:

JÓE, Márcia Maria Sant'Ana. Escrituras de Drummond: Arte em exposição (questões de iconicidade e abstração). Estudos Semióticos. [online] Disponível na Internet via WWW.URL: http://www.fflch.usp.br/dl/semiotica/es. Editor Peter Dietrich. Número 4, São Paulo, 2008.

Acesso em "dia/mês/ano". 